\title{
Detection of intramural scar by electroanatomic mapping versus MRI in patients with non- ischemic cardiomyopathy
}

\author{
Benoit Desjardins ${ }^{1 *}$, Fred Morady ${ }^{2}$, Frank Bogun ${ }^{2}$ \\ From 16th Annual SCMR Scientific Sessions \\ San Francisco, CA, USA. 31 January - 3 February 2013
}

\section{Background}

Ventricular arrhythmias have been described to originate from intramural locations. Intramural scar can be assessed by delayed enhanced magnetic resonance imaging (DE-MRI ). The objective of this study was to determine whether endocardial voltage mapping by catheter can detect the presence and extent of scar deep within the myocardial wall thickness, using DE-MRI as gold standard.

\section{Methods}

In 15 consecutive patients with structural heart disease and without contraindication to MRI, intramural scar was detected by DE-MRI (Fig 1a). All patients underwent endocardial voltage mapping by catheter. Both unipolar and bipolar voltage maps were constructed from the endocardium. The scar on DE-MRI was registered with the electroanatomic map using fiducials (apex, aorta, mitral valve) and a polar representation of the corresponding endocardial voltage was generated (Fig 1b: red points: low voltage, purple points: high voltage, yellow and green points: fiducials).

\section{Results}

On MRI, scar volume was $11.7 \pm 8.0 \mathrm{~cm} 3$, endocardial scar area was $19.3 \pm 13.4 \mathrm{~cm} 2$. Scar thickness was $4.6 \pm 0.7 \mathrm{~mm}$
(39 $\pm 7 \%$ of wall thickness), with a subendocardial rim thickness of $3.3 \pm 1.6 \mathrm{~mm}(26 \pm 13 \%)$ and a subepicardial rim thickness of $4.8 \pm 2.6 \mathrm{~mm}(37 \pm 15 \%)$. Endocardial bipolar voltage measurements were $1.62 \pm 1.73 \mathrm{mV}$ over the scar, $2.12 \pm 2.15 \mathrm{mV}$ in a $1 \mathrm{~cm}$ neighborhood around the scar, and $2.83 \pm 2.34 \mathrm{mV}$ in the more remote myocardium $(\mathrm{p}<0.0001)$. Endocardial unipolar voltage measurements were $4.94 \pm 3.25 \mathrm{mV}$ over the scar, 6.59 $\pm 3.81 \mathrm{mV}$ in a $1 \mathrm{~cm}$ neighborhood around the scar, and $8.32 \pm 3.39 \mathrm{mV}$ in the more remote myocardium $(\mathrm{p}<0.0001)$. Using ROC curves (Fig 1c,d) of the voltage maps, a unipolar cut-off value of $6.78 \mathrm{mV}$ (AUC 0.78) and a bipolar cut-off value of $1.55 \mathrm{mV}$ (AUC 0.69) best separated endocardial measurements overlying scar from the endocardial measurements more remote to the scar.

\section{Conclusions}

Although scar deep within the myocardial wall is far from the tip of the endocardial measurement catheter, its presence and extent can still be detected by endocardial electroanatomic mapping using a combination of unipolar and bipolar voltage, with unipolar voltage being more useful.

\section{Funding}

NIH K23 EB006481. 

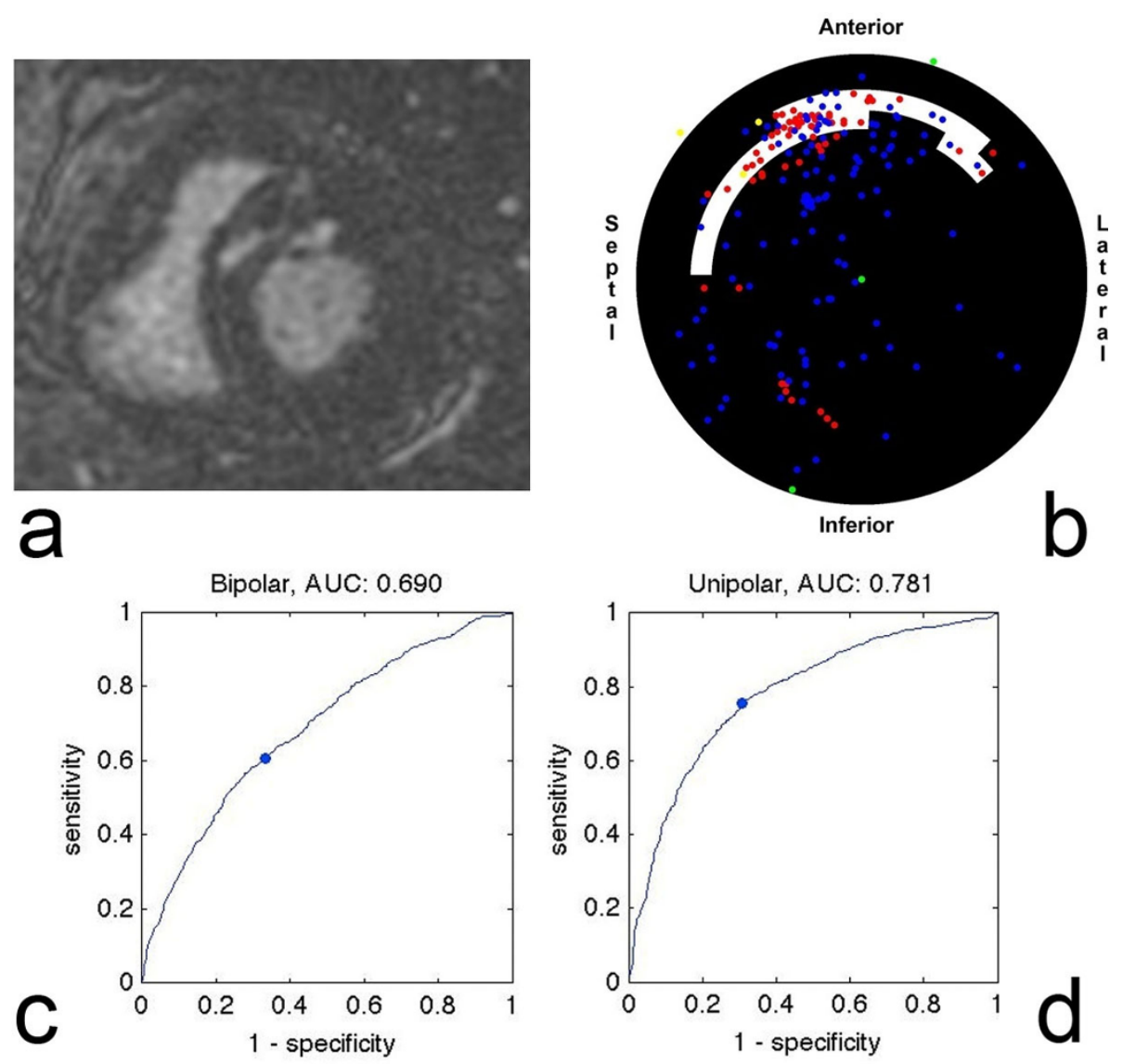

Figure 1

Author details

'Department of Radiology, University of Pennsylvania Medical Center,

Philadelphia, PA, USA. ${ }^{2}$ Medicine, University of Michigan, Ann Arbor, MI, USA.

Published: 30 January 2013

doi:10.1186/1532-429X-15-S1-P65

Cite this article as: Desjardins et al: Detection of intramural scar by electroanatomic mapping versus MRI in patients with non-ischemic cardiomyopathy. Journal of Cardiovascular Magnetic Resonance 201315 (Suppl 1):P65.

Submit your next manuscript to BioMed Central and take full advantage of:

- Convenient online submission

- Thorough peer review

- No space constraints or color figure charges

- Immediate publication on acceptance

- Inclusion in PubMed, CAS, Scopus and Google Scholar

- Research which is freely available for redistribution 